\title{
A combined fracture and mortality risk index useful for treatment stratification in hip fragility fractures
}

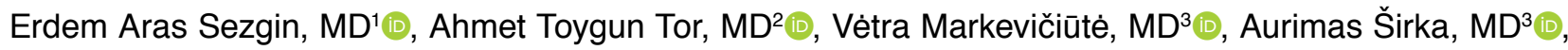

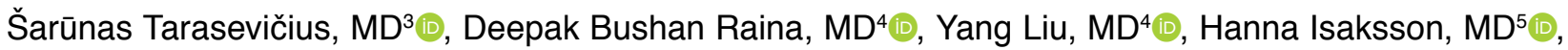 \\ Magnus Tägil, $\mathrm{MD}^{4}{ }^{-}$, Lars Lidgren, $\mathrm{MD}^{4} \mathbb{C}$
}

1Department of Orthopedics and Traumatology, Aksaray University Faculty of Medicine, Aksaray, Turkey

${ }^{2}$ Department of Orthopedics and Traumatology, Gazi University Faculty of Medicine, Ankara, Turkey

${ }^{3}$ Department of Orthopedics and Traumatology, Lithuanian University of Health Sciences, Kaunas, Lithuania

${ }^{4}$ Department of Orthopaedics, Lund University, Clinical Sciences Lund, Lund, Sweden

${ }^{5}$ Department of Biomedical Engineering, Lund University, Lund, Sweden

Fragility fractures of the hip in the elderly are associated with high mortality within in the first postoperative year and high failure rates. Implant-related complication and revision rates in hip fractures have been reported to range from 4.9 to $18.3 \%$, depending on the fracture type. ${ }^{[1-6]}$ Considering the current age-quake, ${ }^{[7]}$ reoperation would contribute substantially to the societal financial burden. ${ }^{[8,9]}$ Strategies for improving the surgical technique in these frail patients with multiple comorbidities are being developed worldwide, mainly focusing on improving the fixation devices, and augmenting the osteoporotic bone around the implant. ${ }^{[10,11]}$ Injection

Received: August 172021

Accepted: September 20, 2021

Published online: November 19, 2021

Correspondence: Erdem Aras Sezgin, MD. Aksaray Üniversitesi Tıp Fakültesi Ortopedi ve Travmatoloji Anabilim Dalı, 68200 Aksaray, Türkiye.

E-mail: sezginmd@hotmail.com

\section{Doi: $10.52312 / j d r s .2021 .382$}

Citation: Sezgin EA, Tor AT, Markevičiūtè $V$, Širka A, Tarasevičius Š, Raina DB, et al. A combined fracture and mortality risk index useful for treatment stratification in hip fragility fractures. Jt Dis Relat Surg 2021;32(3):583-589.

(อ2021 All right reserved by the Turkish Joint Diseases Foundation

This is an open access article under the terms of the Creative Commons Attribution-NonCommercial License, which permits use, distribution and reproduction in any medium, provided the original work is properly cited and is not used for commercial purposes (http://creativecommons.org/licenses/by-nc/4.0/).

\section{ABSTRACT}

Objectives: In this study, we aimed to assess the stratification ability of the Fracture and Mortality Risk Evaluation (FAME) index for reoperation, new fragility fracture, and mortality during one-year follow-up.

Patients and methods: Between November 2018 and July 2019, a total of 94 consecutive hip fragility fracture patients from two centers ( 20 males, 74 females; mean age: $79.3 \pm 8.9$ years; range, 57 to 100 years) were retrospectively analyzed. The patients were classified into high, intermediate, and low fracture and mortality risk groups according to the Fracture Risk Assessment Tool (FRAX) score and Sernbo score, respectively, as well as nine combined categories according to the FAME index. Hospital records were reviewed to identify re-fractures (reoperations, implant failure, new fragility fractures on any site) and mortality at one year following the FAME index classification.

Results: Overall re-fracture and mortality rates were $20.2 \%$ and $33 \%$, respectively. High fracture risk category (FRAX-H) was significantly associated with higher re-fracture (odds ratio [OR]: $2.9,95 \%$ confidence interval $[\mathrm{CI}]: 1-8.2, \mathrm{p}=0.037)$ and mortality rates compared to others (OR: 3.7, 95\% CI: 1.5-9.3, $\mathrm{p}=0.003$ ). The patients classified within the FRAX-H category $(n=35)$ had different mortality rates according to their Sernbo classification; i.e., patients classified as low mortality risk (Sernbo-L) $(n=17)$ had lower mortality rates compared to others in this group $(\mathrm{n}=18)(35.3 \%$ and $66.7 \%$, respectively), indicating a low statistical significance (OR: $0.3,95 \%$ CI: 0.1-1.1, p=0.063). Similarly, within patients classified in Sernbo-L category $(n=64)$, those classified as high fracture risk (FRAX-H) $(\mathrm{n}=17)$ had significantly higher re-fracture rates compared to others in this group $(n=47)(35.3 \%$ and $8.5 \%$, respectively), (OR: 5.9; 95\% CI: 1.4-24.5), $(\mathrm{p}=0.017)$. Multivariate logistic regression analyses adjusting for covariates (age, sex, length of hospital stay and BMI) yielded similar results.

Conclusion: The FAME index appears to be a useful stratification tool for allocating patients in a randomized-controlled trial for augmentation of hip fragility fractures.

Keywords: Augmentation, hip fracture, osteoporosis, risk factors, stratification. 
of polymethyl methacrylate (PMMA) into the femoral neck or trochanter, around a dynamic hip screw or proximal femoral nail has been shown to be effective in previous studies. ${ }^{[12]}$ However, PMMA injection have important drawbacks, due to its non-resorbable nature and not being replaced by native bone which complicates potential revision surgeries. ${ }^{[13]}$ Therefore, finding alternatives to improve immediate fracture fixation and enhance fracture repair is an ongoing area of research. ${ }^{[14-19]}$ Despite promising results in laboratory studies, clinical efficiency of these methods is limited. Moreover, although high-quality randomized-controlled trials (RCTs) are a must for translation of new techniques into practice, they should also be feasible. ${ }^{[19]}$ This poses difficulties, as patients with fragility fractures are known to have scattered bone quality and survival rates. ${ }^{[20,21]}$ Stratification of patients may significantly decrease the size and cost of a RCT producing reliable results and shorten the time for clinical translation.

We earlier developed the Fracture And Mortality Risk Evaluation (FAME) index to stratify patients who would benefit most from improved fixation procedures, namely patients with high risk of mechanical failure and low early postoperative risk of mortality. ${ }^{[20]}$ The FAME index combines three categories of high, intermediate, and low risk for (i) fracture risk, classified by the Fracture Risk Assessment Tool (FRAX) and (ii) mortality risk classified by the Sernbo score, adding up to a total of nine subcategories. ${ }^{[21,22]}$ The FRAX uses basic clinical factors to provide a 10-year probability of a fragility fracture with or without the use of bone mineral density (BMD) measurement. ${ }^{[22]}$ The categorization relies on a 2017 study which introduced age-dependent intervention thresholds based on FRAX scores. ${ }^{[22]}$ The Sernbo score, on the other hand, is a four-element scoring system which was developed to guide the decision between total hip arthroplasty and hemiarthroplasty in hip fracture patients. ${ }^{[21]}$ In 2017, Mellner et al. ${ }^{[21]}$ showed that it could successfully estimate the one-year mortality after surgically treated femoral neck fractures in the elderly. Their follow-up registry based study on over 55,000 hip fracture patients further supported the initial findings. ${ }^{[23]}$ They defined three mortality risk groups using the Sernbo score, which we adopted to develop the FAME index.

In the preliminary study that presented the index, we showed without follow-up that the FAME index applied before surgery in the clinical emergency setting was feasible. ${ }^{[20]}$ In the present study, we aimed to assess the stratification ability of the FAME index for reoperation, new fragility fracture, and mortality during one-year follow-up.

\section{PATIENTS AND METHODS}

This two-center, retrospective study was conducted at Department of Orthopedics and Traumatology, Gazi University Faculty of Medicine and Department of Orthopedics and Traumatology, Lithuanian University of Health Sciences between November 2018 and July 2019. A total of 50 consecutive patients with low-energy fragility fractures of the cervical or intertrochanteric region of the femur admitted for surgery were included in the study. The study centers were from Turkey and from Lithuania, adding up to a total of 100 patients. The patients were operated with osteosynthesis (intramedullary nail, dynamic hip screw, cannulated screws) or arthroplasty, based on the surgeon preference. A total of 17 surgeons performed the procedures. All data to calculate FRAX without BMD and Sernbo scores were recorded on a form created for FAME index as described previously. ${ }^{[20]}$ The patients were classified into high, intermediate, and low fracture risk groups according to FRAX score; high, intermediate, and low mortality risk groups according to Sernbo score, and nine combined categories according to the FAME index (Table I).

\begin{tabular}{|c|c|c|c|c|c|c|c|c|}
\hline \multicolumn{8}{|c|}{ TABLE I } & Classification of patients according to the FAME Index in each center \\
\hline & \multicolumn{2}{|c|}{ Sernbo Low } & \multicolumn{2}{|c|}{ Sernbo Int. } & \multicolumn{2}{|c|}{ Sernbo High } & \multicolumn{2}{|c|}{ Total } \\
\hline & TUR & LIT & TUR & LIT & TUR & LIT & TUR & LIT \\
\hline Frax low & 13 & 11 & 3 & 2 & 1 & 1 & 17 & 14 \\
\hline Frax int. & 7 & 17 & 1 & 1 & 2 & 3 & 10 & 21 \\
\hline Frax high & 9 & 9 & 9 & 1 & 5 & 5 & 23 & 15 \\
\hline Total & 29 & 37 & 13 & 4 & 8 & 9 & 50 & 50 \\
\hline
\end{tabular}


At the end of 12 months based on FAME index classification, hospital records were reviewed to identify fractures on any site sustained during the follow-up period, reoperations, and mortality. Those having incomplete follow-up data $(n=6)$ were excluded from the study. Finally, 94 patients (20 males, 74 females; mean age: $79.3 \pm 8.9$ years; range, 57 to 100 years) were included in the study. A written informed consent was obtained from each patient. The study was conducted in accordance with the principles of the Declaration of Helsinki.

\section{Statistical analysis}

Statistical analysis was performed using the IBM SPSS version 22.0 software (IBM Corp., Armonk, NY, USA). Descriptive data were presented in mean \pm standard deviation (SD), median (min-max) or number and frequency, where applicable. Normality for continuous data were assessed using the Shapiro-Wilk normality test. Descriptive data were analyzed using the chi-square for categorical variables, while the Student t-test or Mann-Whitney U test was used for continuous variables. The chi-square test was used to identify associations and calculate odds ratios (ORs) between categorical variables and both re-fracture and mortality as the endpoints. The Fisher's exact test was used for categorical data with a small expected count $(<5)$. To increase the expected count or to be able use Fisher's exact test, fracture risk, mortality risk and FAME index categories were split into dichotomous variables formed as: high fracture risk (FRAX-H), low mortality risk (Sernbo-L), and high fracture-low mortality risk groups (FAME-HL), respectively versus the rest of the categories. For continuous univariate data, ORs were calculated using univariate binary logistic regression considering re-fracture and mortality at one year as the endpoint. Multivariate binary logistic regressions were used after initial analyses, to adjust for covariates. A $p$ value of $<0.05$ was considered statistically significant with 95\% confidence interval (CI).

\section{RESULTS}

Of a total of 94 patients, 57 were operated with hemiarthroplasty, while the remaining underwent osteosynthesis (intramedullary nailing, $n=29$; dynamic hip screw, $\mathrm{n}=4$; cancellous screw, $\mathrm{n}=4$ ). Overall re-fracture rate and mortality rate at one year was $20.2 \%(\mathrm{n}=19)$ and $33 \%(\mathrm{n}=31)$, respectively. Of the 19 events recorded as re-fractures, nine

\begin{tabular}{|c|c|c|c|c|c|c|c|c|c|c|c|c|}
\hline \multicolumn{13}{|c|}{$\begin{array}{l}\text { TABLE II } \\
\text { Univariate statistics for re-fracture at one year }\end{array}$} \\
\hline & \multicolumn{3}{|c|}{ No re-fracture } & \multicolumn{3}{|c|}{ Re-fracture } & \multicolumn{3}{|c|}{ All } & \multirow[b]{2}{*}{ OR } & \multirow[b]{2}{*}{$95 \% \mathrm{Cl}$} & \multirow[b]{2}{*}{$\mathrm{p}$} \\
\hline & $\mathrm{n}$ & $\%$ & Mean $\pm S D$ & $\mathrm{n}$ & $\%$ & Mean $\pm S D$ & $\mathrm{n}$ & $\%$ & Mean $\pm S D$ & & & \\
\hline Mean age (year) & & & $78.8 \pm 9.3$ & & & $81.3 \pm 6.6$ & & & $79.3 \pm 8.9$ & 1.04 & $1-1.1$ & 0.3 \\
\hline Sex & & & & & & & & & & 1 & $0.3-3.5$ & 0.9 \\
\hline Male & 16 & 80 & & 4 & 20 & & 20 & 21.3 & & & & \\
\hline Female & 59 & 79.7 & & 15 & 20.3 & & 74 & 78.7 & & & & \\
\hline Hospital of follow-up & & & & & & & & & & 0.8 & $0.3-2$ & 0.6 \\
\hline Turkey & 34 & 77.3 & & 10 & 22.7 & & 44 & 46.8 & & & & \\
\hline Lithuania & 41 & 82 & & 9 & 18 & & 50 & 53.2 & & & & \\
\hline Mean BMI (kg/m²) & & & $24.8 \pm 5.1$ & & & $26.1 \pm 5.5$ & & & $25 \pm 5.2$ & 1.05 & $1-1.2$ & 0.3 \\
\hline Fracture risk & & & & & & & & & & 2.9 & $1-8.2$ & $0.037^{*}$ \\
\hline Rest of the categories & 51 & 86.4 & & 8 & 13.6 & & 59 & 62.8 & & & & \\
\hline FRAX-H & 24 & 68.6 & & 11 & 31.4 & & 35 & 37.2 & & & & \\
\hline Mortality risk & & & & & & & & & & 0.4 & $0.2-1.2$ & 0.1 \\
\hline Sernbo-L & 54 & 84.4 & & 10 & 15.6 & & 64 & 68.1 & & & & \\
\hline Rest of the categories & 21 & 70 & & 9 & 30 & & 30 & 31.9 & & & & \\
\hline FAME category & & & & & & & & & & 2.7 & $0.8-8.6$ & 0.1 \\
\hline FAME-HL & 11 & 64.7 & & 6 & 35.3 & & 17 & 18.1 & & & & \\
\hline Rest of the categories & 64 & 83.1 & & 13 & 16.9 & & 77 & 81.9 & & & & \\
\hline
\end{tabular}




\begin{tabular}{|c|c|c|c|c|c|c|c|c|c|c|c|c|}
\hline \multicolumn{13}{|c|}{$\begin{array}{l}\text { TABLE III } \\
\text { Univariate statistics for mortality at one year }\end{array}$} \\
\hline & \multicolumn{3}{|c|}{ Alive } & \multicolumn{3}{|c|}{ Dead } & \multicolumn{3}{|c|}{ All } & \multirow[b]{2}{*}{ OR } & \multirow[b]{2}{*}{$95 \% \mathrm{Cl}$} & \multirow[b]{2}{*}{$p$} \\
\hline & $\mathrm{n}$ & $\%$ & Mean $\pm S D$ & $\mathrm{n}$ & $\%$ & Mean $\pm S D$ & $\mathrm{n}$ & $\%$ & Mean $\pm S D$ & & & \\
\hline Mean age (year) & & & $78.3 \pm 9.4$ & & & $81.1 \pm 7.4$ & & & $79.3 \pm 8.9$ & 1.04 & $1-1.1$ & 0.2 \\
\hline Sex & & & & & & & & & & 3.5 & $1-12.8$ & 0.054 \\
\hline Male & 17 & 85 & & 3 & 15 & & 20 & 21.3 & & & & \\
\hline Female & 46 & 62.2 & & 28 & 37.8 & & 74 & 78.7 & & & & \\
\hline Hospital of follow-up & & & & & & & & & & 0.9 & $0.4-2.2$ & 0.8 \\
\hline Turkey & 29 & 65.9 & & 15 & 34.1 & & 44 & 46.8 & & & & \\
\hline Lithuania & 34 & 68 & & 16 & 32 & & 50 & 53.2 & & & & \\
\hline Mean BMI (kg/m²) & & & $24.8 \pm 5$ & & & $25.5 \pm 5.8$ & & & $25 \pm 5.2$ & 1.03 & $1-1.1$ & 0.6 \\
\hline Fracture risk & & & & & & & & & & 3.7 & $1.5-9.3$ & $0.003^{*}$ \\
\hline Rest of the categories & 46 & 78 & & 13 & 22 & & 59 & 62.8 & & & & \\
\hline FRAX-H & 17 & 48.6 & & 18 & 51.4 & & 35 & 37.2 & & & & \\
\hline Mortality risk & & & & & & & & & & 0.4 & $0.2-1.02$ & 0.053 \\
\hline Sernbo-L & 47 & 73.4 & & 17 & 26.6 & & 64 & 68.1 & & & & \\
\hline Rest of the categories & 16 & 53.3 & & 14 & 46.7 & & 30 & 31.9 & & & & \\
\hline FAME category & & & & & & & & & & 1.1 & $0.4-3.4$ & 0.8 \\
\hline FAME-HL & 11 & 64.7 & & 6 & 35.3 & & 17 & 18.1 & & & & \\
\hline Rest of the categories & 52 & 67.5 & & 25 & 32.5 & & 77 & 81.9 & & & & \\
\hline
\end{tabular}

were reoperations (cut-out, $n=5$; infection, $n=2$; periprosthetic fracture, $n=1$; pseudoarthrosis, $n=1$ ) and 10 were fractures located in other sites.

Age, sex, length of hospital stay, Sernbo score, and FAME index were not statistically significant predictors of any endpoint. However, high-fracture risk category (FRAX-H) was significantly associated with higher re-fracture and mortality rates compared to others (Tables II and III).
Although overall mortality was significantly higher in the FRAX-H category (Table 3), for patients in this category $(n=35)$, who were also classified as Sernbo-L (FAME-HL category, $n=17$ ) had lower mortality rates than the others in FRAX-H category $(n=18)(35.3 \%$ and $66.7 \%$, respectively); however, it reached a low statistical significance (OR 0.3 [95\% CI: 0.1-1.1], $\mathrm{p}=0.063$ ). Similarly, for patients in the Sernbo-L category $(n=64)$, the patients who were also classified as FRAX-H (FAME-HL

\begin{tabular}{|c|c|c|c|c|c|c|}
\hline \multicolumn{7}{|c|}{$\begin{array}{rll}\text { TABLE IV }\end{array}$} \\
\hline & \multicolumn{2}{|c|}{ Model 1} & \multicolumn{2}{|c|}{ Model 2} & \multicolumn{2}{|c|}{ Model 3} \\
\hline & OR & $95 \% \mathrm{Cl}$ & OR & $95 \% \mathrm{Cl}$ & OR & $95 \% \mathrm{Cl}$ \\
\hline Age & 1 & $1-1.1$ & 1 & 0.9-1.1 & 1.1 & $1-1.1$ \\
\hline Sex & 0.3 & $0.1-1.6$ & 0.7 & $0.2-2.8$ & 0.5 & $0.1-2$ \\
\hline Hospital of follow-up & 0.9 & $0.3-2.6$ & 0.8 & $0.3-2.3$ & 0.7 & $0.2-2$ \\
\hline Body mass index & 1.1 & $1-1.2$ & 1.1 & $1-1.2$ & 1.1 & $1-1.2$ \\
\hline FRAX (dichotomous) & $4.1^{*}$ & $1.1-15.9$ & & & & \\
\hline Sernbo (dichotomous) & & & 0.5 & $0.1-1.8$ & & \\
\hline FAME (dichotomous) & & & & & 3 & $0.8-10.4$ \\
\hline
\end{tabular}




\begin{tabular}{|c|c|c|c|c|c|c|}
\hline \multicolumn{7}{|c|}{$\begin{array}{r}\text { TABLE V } \\
\text { Multivariate logistic regression analysis for mortality at one year, }\end{array}$} \\
\hline & \multicolumn{2}{|c|}{ Model 1} & \multicolumn{2}{|c|}{ Model 2} & \multicolumn{2}{|c|}{ Model 3} \\
\hline & OR & $95 \% \mathrm{Cl}$ & OR & $95 \% \mathrm{Cl}$ & OR & $95 \% \mathrm{Cl}$ \\
\hline Age & 1 & $1-1.1$ & 1 & $0.9-1.1$ & 1 & $1-1.1$ \\
\hline Sex & 1.7 & $0.4-7.4$ & 3.1 & $0.8-12.6$ & 2.9 & $0.7-11.6$ \\
\hline Hospital of follow-up & 1.2 & $0.5-3$ & 1.1 & $0.4-2.8$ & 1 & $0.4-2.4$ \\
\hline Body mass index & 1 & $1-1.1$ & 1 & $0.9-1.2$ & 1 & $0.9-1.1$ \\
\hline FRAX (dichotomous) & $3.2^{*}$ & $1.1-9.1$ & & & & \\
\hline Sernbo (dichotomous) & & & 0.4 & $0.1-1.3$ & & \\
\hline FAME (dichotomous) & & & & & 0.9 & $0.3-2.7$ \\
\hline
\end{tabular}

category, $\mathrm{n}=17$ ) had a significantly higher risk of re-fracture than the others in the Sernbo-L category $(\mathrm{n}=47)(35.3 \%$ and $8.5 \%$, respectively) (OR: $5.9 ; 95 \%$ CI: 1.4-24.5), $(\mathrm{p}=0.017)$.

When the FRAX-H, Sernbo-L, and FAME-HL categories were analyzed in the multivariate binary logistic regression analysis adjusting for covariates (i.e., age, sex, length of hospital stay, body mass index), the results remained unchanged (Tables IV and V).

\section{DISCUSSION}

The present study results showed that combining FRAX and Sernbo scores could produce a plausible stratification tool for patients with fragility fractures in the hip. Risk stratification with FRAX alone could identify the patients with high risk of re-fracture. However, the parameters used to calculate the FRAX score are also commonly considered as surrogate markers of frailty, which possibly is the reason for FRAX-H category also having a significantly higher mortality. Therefore, we believe that using FRAX alone would not be feasible for stratifying hip fracture patients to be assigned in a RCT on augmentation. When the mortality risk classification according to the Sernbo score was utilized in this group, the patients with about half the mortality could be identified, although with a low statistical significance. Similarly, Sernbo-L category was hypothesized to have lower mortality than the other categories, and it had also low significance. Highlighting the relevance of our proposed combined approach in this category, the patients categorized as FRAX-H had a significantly higher risk of re-fracture. Thus, patients classified as high fracture-low mortality risk in the FAME index could have a higher risk of mechanical failure.

Identifying patients with a higher risk of mortality following a hip fracture and addressing their needs appropriately is undeniably important to improve general care and survival rates. ${ }^{[21]}$ In a very recent study on 215,672 hip fragility fractures from the French National Health database, Roux et al. ${ }^{[24]}$ reported that, in patients hospitalized for a hip fracture, the 12-month mortality rate was $16.6 \%$ and the rate of re-fracture at any site was $6.6 \%$, indicating the burden of mortality. However, it should also be noted that occurrence of re-fracture substantially contributes to the mortality risk. ${ }^{[25]}$ Therefore, by identifying the patients who have a lower bone quality while having a relatively lower risk of death, researchers can focus efforts and resources on developing strategies against mechanical failure and subsequent excess mortality more efficiently.

Recent research has focused on improving implant fixation, implant design and type of biomaterials, in combination with bone active molecules. ${ }^{[26,27]}$ Recently, Kok et al. ${ }^{[15]}$ reported that fixation could be improved with utilization of calcium sulfate/hydroxyapatite (CaS/HA) biomaterial injected through cannulated hip screws, increasing the pullout strength on synthetic bone models. Another recent in vivo study by Raina et al. $^{[28]}$ found that the tissue engineering strategy of using $\mathrm{CaS} / \mathrm{HA}$ ceramic biomaterial to locally deliver zoledronic acid (ZA) with or without recombinant human bone morphogenic protein-2 in femoral necks of osteoporotic rats had potential to regenerate cancellous bone in 
the femoral neck canal and, therefore, enhance fixation and implant anchorage in osteoporotic bone. As ceramic biomaterial alone may have a limited effect on bone formation, its utilization as a carrier for local delivery of ZA emerges as a promising strategy against mechanical failure of hip fractures. These new augmentation strategies based on tissue engineering with their ability to initiate peri-implant cancellous bone formation could mitigate fixation failures and has potential to replace conventional PMMA-based, augmentation methods in the current clinical practice. The use of FAME index to stratify patients for inclusion in a RCT with ceramic materials can accelerate the clinical translation.

Nonetheless, there are several limitations to our study. Despite enrolling the same number of consecutive patients in each center and demographics, fracture and mortality rates being similar, as well as distribution of patients in different FAME categories, we consider selection bias and heterogeneity of patients as limitations related to the retrospective design. Moreover, six patients from the Turkish cohort were excluded from the analysis due to loss of follow-up, which further limited the sample size and potentially further increased heterogeneity. Another limitation is that FRAX has not previously been studied as a predictor for mechanical failure following fragility fractures of the hip. Nevertheless, our aim was to assess its effectiveness in stratifying patients according to bone quality which was portrayed by the re-fracture outcomes. This study is limited in size which potentially can lead to excluding patients that could potentially benefit from augmentation. Yet, augmentation is on its early stage in translation into clinical practice and, therefore, the initial objective would be to test whether it prevents fixation failure and revisions at a reasonable cost and with a low risk of adverse events. With further developments in this field, modifications to the FAME index can be done to increase its ability to identify suitable patients for inclusion in registry-nested RCT trials. ${ }^{[27,28]}$

In conclusion, the FAME index appears to be a useful stratification tool for allocating patients in a RCT studying augmentation of hip fragility fractures. Further well-designed, large-scale, prospective RCTs are warranted to draw more reliable conclusions on this subject.

\section{Declaration of conflicting interests}

LL is a board member of Bone Support AB, Lund, Sweden and Ortho Cell, Australia. The authors declared no conflicts of interest with respect to the authorship and/or publication of this article.

\section{Funding}

The financial support to the researchers was granted by VINNOVA innovation agency in Sweden (grant 2017-00269), VR-The Swedish Research Council (grant 2015-06717) and the Foundation for Disabled people in Scania, Sweden. The funding bodies had no role in the design of the study, data collection, analysis, and interpretation of data or in writing the manuscript.

\section{REFERENCES}

1. Metcalfe D, Judge A, Perry DC, Gabbe B, Zogg CK, Costa ML. Total hip arthroplasty versus hemiarthroplasty for independently mobile older adults with intracapsular hip fractures. BMC Musculoskelet Disord 2019;20:226.

2. Zhao Y, Fu D, Chen K, Li G, Cai Z, Shi Y, et al. Outcome of hemiarthroplasty and total hip replacement for active elderly patients with displaced femoral neck fractures: a meta-analysis of 8 randomized clinical trials. PLoS One 2014;9:e98071.

3. Nherera L, Trueman P, Horner A, Watson T, Johnstone AJ. Comparison of a twin interlocking derotation and compression screw cephalomedullary nail (InterTAN) with a single screw derotation cephalomedullary nail (proximal femoral nail antirotation): a systematic review and metaanalysis for intertrochanteric fractures. J Orthop Surg Res 2018;13:46.

4. Selim A, Ponugoti N, Naqvi AZ, Magill H. Cephalomedullary nailing versus dynamic hip screw with trochanteric stabilisation plate for the treatment of unstable per-trochanteric hip fractures: A meta-analysis. J Orthop Surg Res 2021;16:47.

5. Smith L, Albersheim M, Blaschke BL, Parikh HR, Solfelt DA, Van Heest AE, et al. Trend and economic implications of implant selection in the treatment of intertrochanteric hip fractures: A review of the American Board of Orthopaedic Surgery Database From 2007 to 2017. J Am Acad Orthop Surg 2021;29:789-95.

6. Ekinci Y, Gürbüz K, Batın S, Kahraman M, Doğar F, Kaya Erten Z. A multicenter intertrochanteric fracture study in the elderly: Hemiarthroplasty versus proximal femoral nailing. Jt Dis Relat Surg 2020;31:209-17.

7. Bergström U, Jonsson H, Gustafson Y, Pettersson U, Stenlund H, Svensson O. The hip fracture incidence curve is shifting to the right. Acta Orthop 2009;80:520-4.

8. Williamson S, Landeiro F, McConnell T, Fulford-Smith L, Javaid MK, Judge A, et al. Costs of fragility hip fractures globally: A systematic review and meta-regression analysis. Osteoporos Int 2017;28:2791-800.

9. Hernlund E, Svedbom A, Ivergård M, Compston J, Cooper C, Stenmark J, et al. Osteoporosis in the European Union: medical management, epidemiology and economic burden. A report prepared in collaboration with the International Osteoporosis Foundation (IOF) and the European Federation of Pharmaceutical Industry Associations (EFPIA). Arch Osteoporos 2013;8:136.

10. Dreinhöfer KE, Mitchell PJ, Bégué T, Cooper C, Costa ML, Falaschi $\mathrm{P}$, et al. A global call to action to improve the care of people with fragility fractures. Injury 2018;49:1393-7.

11. Morochovič R, Kňazovický M, Paulo M, Takáčová K, Burda R. Reversed Z-effect and Z-effect phenomena in femoral neck fracture treated with a dynamic locking plate fixation: Case report. Jt Dis Relat Surg 2021;32:249-52. 
12. Goodnough LH, Wadhwa H, Tigchelaar SS, DeBaun MR, Chen MJ, Graves ML, et al. Indications for cement augmentation in fixation of geriatric intertrochanteric femur fractures: A systematic review of evidence. Arch Orthop Trauma Surg 2021.

13. Heini PF, Franz T, Fankhauser C, Gasser B, Ganz R. Femoroplasty-augmentation of mechanical properties in the osteoporotic proximal femur: A biomechanical investigation of PMMA reinforcement in cadaver bones. Clin Biomech (Bristol, Avon) 2004;19:506-12.

14. Kok J, Širka A, Grassi L, Raina DB, Tarasevičius Š, Tägil $\mathrm{M}$, et al. Fracture strength of the proximal femur injected with a calcium sulfate/hydroxyapatite bone substitute. Clin Biomech (Bristol, Avon) 2019;63:172-8.

15. Kok J, Širka A, Liu Y, Tarasevičius Š, Belickas J, Tägil M, et al. Augmenting a dynamic hip screw with a calcium sulfate/ hydroxyapatite biomaterial. Med Eng Phys 2021;92:102-9.

16. Širka A, Raina DB, Isaksson H, Tanner KE, Smailys A, Kumar A, et al. Calcium sulphate/hydroxyapatite carrier for bone formation in the femoral neck of osteoporotic rats. Tissue Eng Part A 2018;24:1753-64.

17. Kammerlander C, Neuerburg C, Verlaan JJ, Schmoelz W, Miclau T, Larsson S. The use of augmentation techniques in osteoporotic fracture fixation. Injury 2016;47 Suppl 2:S36-43.

18. Mattsson P, Alberts A, Dahlberg G, Sohlman M, Hyldahl $\mathrm{HC}$, Larsson S. Resorbable cement for the augmentation of internally-fixed unstable trochanteric fractures. A prospective, randomised multicentre study. J Bone Joint Surg [Br] 2005;87:1203-9.

19. Kim SJ, Park HS, Lee DW, Lee JW. Is calcium phosphate augmentation a viable option for osteoporotic hip fractures? Osteoporos Int 2018;29:2021-8.

20. Sezgin EA, Markevičiūtè V, Širka A, Tarasevičius Š, Raina $\mathrm{DB}$, Isaksson $\mathrm{H}$, et al. Combined fracture and mortality risk evaluation for stratifying treatment in hip fracture patients: A feasibility study. Jt Dis Relat Surg 2020;31:163-8.

21. Mellner C, Eisler T, Börsbo J, Brodén C, Morberg P, Mukka $\mathrm{S}$. The Sernbo score predicts 1-year mortality after displaced femoral neck fractures treated with a hip arthroplasty. Acta Orthop 2017;88:402-6.

22. Compston J, Cooper A, Cooper C, et al. UK clinical guideline for the prevention and treatment of osteoporosis. Arch Osteoporos 2017;12:43.

23. Mellner C, Hedström M, Hommel A, Sköldenberg O, Eisler T, Mukka S. The Sernbo score as a predictor of 1-year mortality after hip fracture: a registry study on 55,716 patients. Eur J Trauma Emerg Surg 2020 [Online ahead of print].

24. Roux C, Thomas T, Paccou J, Bizouard G, Crochard A, Toth E, et al. Refracture and mortality following hospitalization for severe osteoporotic fractures: The Fractos Study. JBMR Plus 2021;5:e10507.

25. Bliuc D, Nguyen ND, Nguyen TV, Eisman JA, Center JR. Compound risk of high mortality following osteoporotic fracture and refracture in elderly women and men. J Bone Miner Res 2013;28:2317-24.

26. Stravinskas M, Tarasevicius S, Laukaitis S, Nilsson M, Raina DB, Lidgren L. A ceramic bone substitute containing gentamicin gives good outcome in trochanteric hip fractures treated with dynamic hip screw and in revision of total hip arthroplasty: A case series. BMC Musculoskelet Disord 2018;19:438.

27. Raina DB, Larsson $D$, Sezgin EA, Isaksson $H$, Tägil $M$, Lidgren L. Biomodulation of an implant for enhanced boneimplant anchorage. Acta Biomater 2019;96:619-30.

28. Raina DB, Širka A, Qayoom I, Teotia AK, Liu Y, Tarasevicius $\mathrm{S}$, et al. Long-term response to a bioactive biphasic biomaterial in the femoral neck of osteoporotic Rats. Tissue Eng Part A 2020;26:1042-51. 